\title{
Internet-based modular program BADI for adjustment disorder: protocol of a randomized controlled trial
}

\author{
Paulius Skruibis ${ }^{1}$, Jonas Eimontas ${ }^{1}$, Migle Dovydaitiene ${ }^{2}$, Egle Mazulyte ${ }^{1}$, Paulina Zelviene ${ }^{1}$ \\ and Evaldas Kazlauskas ${ }^{1 *}$ (i)
}

\begin{abstract}
Background: Adjustment disorder is one of the most common mental health diagnoses. Still it receives relatively little attention from researchers trying to establish best interventions to treat it. With high prevalence of stressful life events, which might be leading to adjustment disorder, and limited resources of mental health service providers, online interventions could be a very practical way of helping people who have these disorders or are in the risk to develop them. The proposed study protocol is aimed to describe a randomized controlled trial of an internet-based modular intervention for adjustment disorder as it is defined in a proposal for the ICD-11.

Methods/design: This study is a two-armed Randomized Controlled Trial (RCT) to examine the effectiveness of a web-based intervention BADI (Brief Adjustment Disorder Intervention) for adjustment disorder symptoms. BADI has four modules: Relaxation, Time management, Mindfulness and Strengthening relationships. It is based on stress and coping research and integrates evidence-based treatment approaches such as Cognitive Behavioural therapy (CBT), mindfulness and body-mind practices, as well as exercises for enhancing social support. Primary outcome of the study are symptoms of adjustment disorder and well-being. Engagement into the program and motivation for change is a secondary outcome. All participants after completing the baseline assessment are randomly assigned to one of the two groups: either to the one in which participant will instantly gain access to the BADI intervention or a group in which participants will be given access to the BADI program after waiting one month. Participants of $\mathrm{BADI}$ can choose exercises of the program flexibly. There is no particular order in which the exercises should be completed.
\end{abstract}

Discussion: Study will provide new insights of modular internet-based interventions efficacy for adjustment disorders. The study will also provide information about the role of motivation and expectancies on engagement in modular internet-based interventions. In case this RCT supports effectiveness of fully automated version of BADI, it could be used very broadly. It could become a cost-effective and accessible intervention for adjustment disorder.

Trial registration: The study was retrospectively registered with the Australian and New Zealand Clinical Trials Registry with the registration number ACTRN12616000883415. Registered 5 July, 2016.

Keywords: Adjustment disorder, Internet-based, Online, intervention, EHealth, RCT, Stress

\footnotetext{
* Correspondence: evaldas.kazlauskas@fsf.vu.lt

${ }^{1}$ Department of Clinical and Organizational Psychology, Vilnius University,

Universiteto str. 9/1, Vilnius 01513, Lithuania

Full list of author information is available at the end of the article
} 


\section{Background}

\section{The new concept of adjustment disorder}

Adjustment disorder is one of the most common mental health diagnoses around the world [1]. Despite that, it has been considered a poorly defined area of psychopathology, therefore conceptual changes were proposed both for DSM-5 and ICD-11 [2-5].

In DSM-5 adjustment disorders have been classified under trauma and stress related disorders for the first time. However, some scholars argue that they still remain rather loosely defined [5]. Proposals for ICD-11 conceptualize adjustment disorder as a maladaptive reaction to identifiable stressors [4]. Intrusive preoccupations with the stressor, avoidance and failure to adapt should separate this disorder from normal reactions and no requirements for severity of the stressor should distinguish it from PTSD $[3,4,6]$.

This new conception of adjustment disorder, that was proposed for ICD-11, was employed in a representative national wide survey of general population in Germany [2]. Results of the study indicated $0.9 \%$ prevalence of adjustment disorder fulfilling clinically significant impairment criterion, and $1.4 \%$ without fulfilling this criterion. This study also established life events that were most frequently associated with adjustment disorder: serious illness, conflict with neighbours and job-related conflict. The proposed new structure of the adjustment disorder was also recently validated in a Lithuanian representative population sample [7]. This study supported the two core symptom adjustment disorder structure.

\section{Interventions for Adjustment disorder}

In addition to vagueness of definitions, adjustment disorder received relatively little attention from researchers trying to establish best interventions to treat it [5, 8]. As evidence for the benefits of pharmacological treatment is extremely limited, psychotherapeutic interventions are considered as treatment of choice [5, 8, 9]. Among specific psychotherapeutic approaches the following were tried without clear consensus which are the most effective: supportive, psychoeducational, cognitive, psychodynamic, Interpersonal, ego-enhancing, problem-solving, eye movement desensitization and reprocessing, support groups, "mirror psychotherapy" and "activating intervention" $[5,8,9]$.

\section{E-health advantages in treating adjustment disorder}

Having in mind high prevalence of stressful life events, which might be leading to adjustment disorder, and limited resources of mental health service providers, online interventions could be a very practical way of helping people who have these disorders or are in the risk of developing them. Especially if these interventions could be provided automatically, thus requiring little human resources.

Studies of another more severe stress related disorder posttraumatic stress disorder (PTSD) - show that stigmatization of help, practical issues such as incompatible time, transportation problems, financial problems, lack of professional services in residential area, negative prejudice about the effectiveness and availability of help are among those barriers that prevent people from getting help they really need $[10,11]$. Internet-based interventions might be a good way to remove at least some of these obstacles for treatment.

A meta-analysis of the effectiveness of internet-based psychotherapeutic interventions for various conditions showed that these interventions could be as effective as face to face therapies [12]. A more recent meta-analysis of telehealth treatments supported the use of telehealth treatments specifically for individuals with PTSD-related symptoms [10]. To our knowledge there are only two telehealth interventions developed specifically for adjustment disorders [8]. Both interventions have not been evaluated in large-scale empirical studies yet.

We have developed a web-based intervention BADI (Brief Adjustment Disorder Intervention) to help people to deal with adjustment disorder symptoms after stressful life events. This paper reports on the protocol of a RCT examining the effectiveness of this intervention.

\section{Aims of the study}

There are two aims of this RCT: 1) to evaluate the effectiveness of an internet-based modular intervention for adjustment disorder (BADI); 2) to examine correlations between effectiveness, motivation, expectations, drop-out and adherence.

\section{Methods/design}

BADI is an open access internet-based modular intervention for adjustment disorders registered with the Australian and New Zealand Clinical Trials Registry with the registration number ACTRN12616000883415. The study was considered and approved by Vilnius University Psychology Research Ethics Committee. This study follows CONSORT E-HEALTH guidelines [13]. Figure 1 represents procedure of the study schematically.

\section{Setting}

Participation in the study is online only. Vilnius University is the administering institution of the study website.

\section{BADI intervention}

BADI program is a structured short-term online intervention program addressed to people with adjustment disorders or those who are experiencing stressful life events and have a risk for adjustment disorders. BADI 


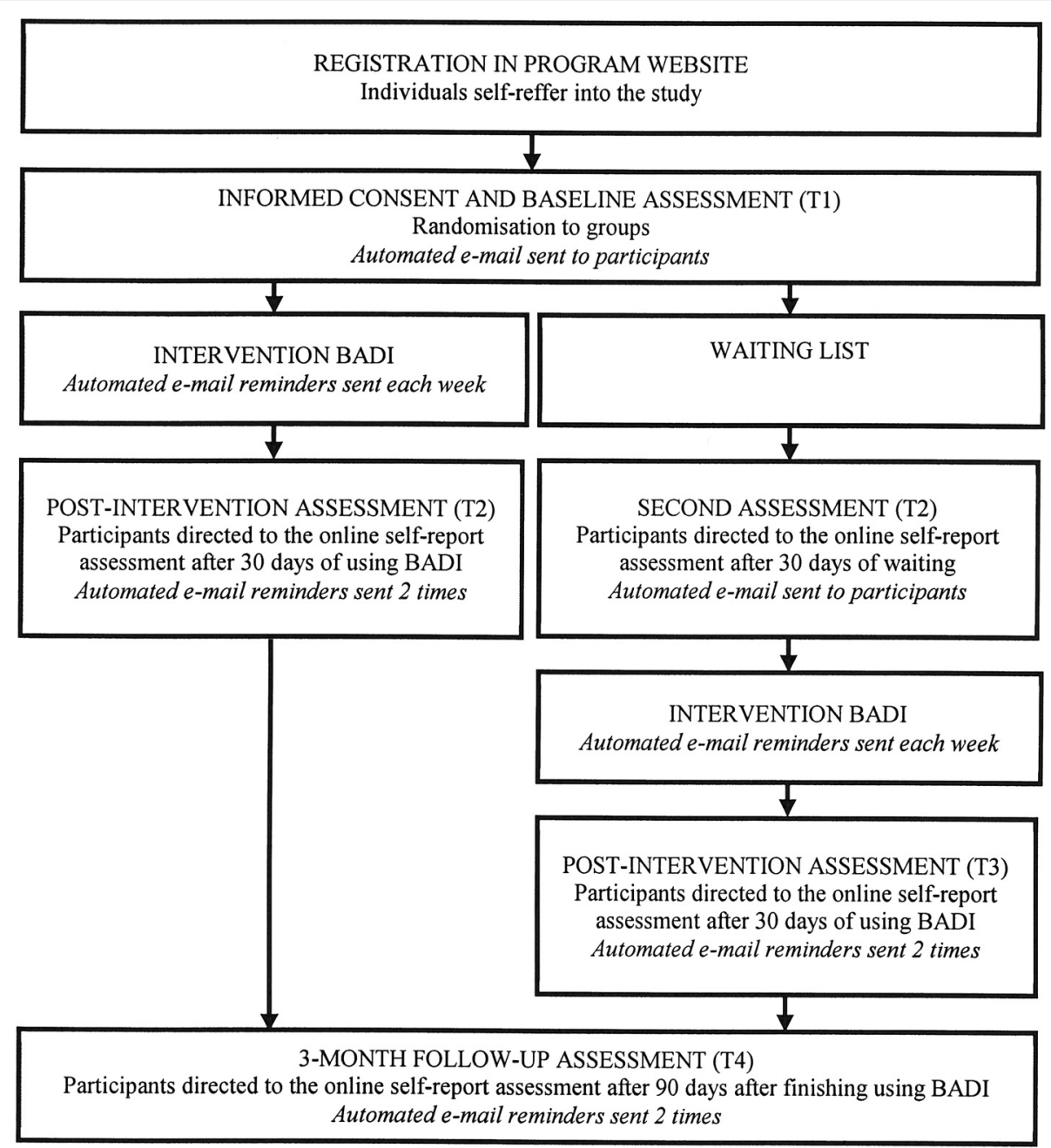

Fig. 1 Flow chart of the study

program is focused upon enhancing process of psychological resilience, utilizing personal and social resources and developing better coping skills.

The program consists of four modules: Relaxation (named "Body"), Time management (named "Time"), Mindfulness (named "Space") and Strengthening relationships (named "Relationships"). Descriptions of exercises are provided in Table 1.

BADI program is based on stress and coping research and integrates evidence-based modern treatment approaches such as Cognitive Behavioural therapy (CBT), mindfulness and body-mind practices, as well as exercises for enhancing social support.

Relaxation module exercises were selected considering research on the topic. Progressive muscle relaxation effectiveness studies demonstrated that it could be a useful technique in various fields of medicine [14-16]. BADI relaxation module also includes breath and body scanning exercises which are based on combined body and mindfulness principles [17-20].

The focus of Time management module is to stimulate problem-focused stress coping [21]. The analysis of coping strategies revealed that problem-focused coping is more efficient than emotion-focused [22] and is related to greater health benefits and better adjustment.

BADI mindfulness module is based on a review of rapidly growing evidence of effect of mindfulness on stress and well-being (e.g. [23-26]).

Social support is another important part of effective coping with stress [27]. BADI relationships module includes partner encouragement exercise, assertive message and appreciation which enhance stress coping through open communication and social support $[18,21]$.

Exercises take from 5 to $15 \mathrm{~min}$ to complete. The participant may complete as many or as few modules as 
Table 1 BADI content

\begin{tabular}{|c|c|c|c|}
\hline Module & Exercise & Aim of the exercise & Activity in the module \\
\hline \multirow[t]{3}{*}{ Relaxation "Body" } & $\begin{array}{l}\text { Progressive } \\
\text { muscle } \\
\text { relaxation }\end{array}$ & $\begin{array}{l}\text { Relieving muscle tension, relaxing body, } \\
\text { enhancing stress resistance. Learning how to } \\
\text { actively relax in stressful situations }\end{array}$ & $\begin{array}{l}\text { Progressive relaxation using voice-guided instructions. } \\
\text { Participant performs progressive muscle relaxation } \\
\text { exercise. Duration 5-10 min. }\end{array}$ \\
\hline & $\begin{array}{l}\text { Breathing } \\
\text { awareness }\end{array}$ & Recognising breathing pattern and relaxing & $\begin{array}{l}\text { Structured self-observation exercise. Participant concentrates } \\
\text { on breathing and present moment. Duration 5-10 min. }\end{array}$ \\
\hline & Body scanning & $\begin{array}{l}\text { Focusing mindful attention, reducing tension, } \\
\text { achieving mind-body balance }\end{array}$ & $\begin{array}{l}\text { Voice-guided structured exercise. Participant focuses on } \\
\text { breathing and sensations. Duration 5-10 min. }\end{array}$ \\
\hline \multirow[t]{3}{*}{$\begin{array}{l}\text { Time } \\
\text { management } \\
\text { "Time" }\end{array}$} & $\begin{array}{l}\text { Priorities of the } \\
\text { day }\end{array}$ & $\begin{array}{l}\text { Recognising core values, choosing between } \\
\text { alternatives, establishing personal guidelines }\end{array}$ & $\begin{array}{l}\text { Voice-guided fantasy exercise and pencil-paper list making. } \\
\text { Participant plans and implements important day activities. } \\
\text { Duration 5-15 min. }\end{array}$ \\
\hline & Accomplishment & $\begin{array}{l}\text { Revealing valuable task of the day, planning action } \\
\text { and execution }\end{array}$ & $\begin{array}{l}\text { Participant writes down three tasks, then chooses one and } \\
\text { divides it into smaller pieces. The participant then makes a } \\
\text { schedule for those divided taskas. Duration 5-10 min. }\end{array}$ \\
\hline & $\begin{array}{l}\text { Planning } \\
\text { pleasant } \\
\text { activities }\end{array}$ & $\begin{array}{l}\text { Making decisions, taking actions, preventing } \\
\text { distress, creating positive experiences }\end{array}$ & $\begin{array}{l}\text { Brainstorming, planning and implementing homework } \\
\text { assignment. Participant plans and implements pleasant } \\
\text { activity. Duration 5-10 min. }\end{array}$ \\
\hline \multirow[t]{3}{*}{$\begin{array}{l}\text { Mindfulness } \\
\text { "Space" }\end{array}$} & $\begin{array}{l}\text { Walking } \\
\text { meditation }\end{array}$ & $\begin{array}{l}\text { Establishing posture, concentrating on action, } \\
\text { relaxing and focusing attention }\end{array}$ & $\begin{array}{l}\text { Voice-guided structured exercise. Participant performs } \\
\text { relaxation and meditation while walking. Duration 5-10 min. }\end{array}$ \\
\hline & $\begin{array}{l}\text { Seeing } \\
\text { meditation }\end{array}$ & $\begin{array}{l}\text { Anchoring attention, relaxing and concentrating } \\
\text { on the moment }\end{array}$ & $\begin{array}{l}\text { Voice-guided structured exercise. Participant performs } \\
\text { sight concentration exercise focusing attention at the } \\
\text { moment. Duration 5-10 min. }\end{array}$ \\
\hline & $\begin{array}{l}\text { Letting go of } \\
\text { thoughts }\end{array}$ & $\begin{array}{l}\text { Concentrating on sensations, relieving negative } \\
\text { thoughts and tension }\end{array}$ & $\begin{array}{l}\text { Voice-guided structured exercise. Participant performs } \\
\text { visualisation exercise. Duration 5-10 min. }\end{array}$ \\
\hline \multirow[t]{3}{*}{$\begin{array}{l}\text { Strengthening } \\
\text { relationships } \\
\text { "Relationships" }\end{array}$} & $\begin{array}{l}\text { Partners' } \\
\text { encouragement }\end{array}$ & $\begin{array}{l}\text { Developing empathy, sharing partners' feelings, } \\
\text { coping with interpersonal stress and preventing } \\
\text { conflict }\end{array}$ & $\begin{array}{l}\text { Reflexion, structured action planning and implementation } \\
\text { exercise. Participant is asked to choose one way to } \\
\text { encourage partner and realise this at the moment. } \\
\text { Duration } 10-15 \text { min. }\end{array}$ \\
\hline & $\begin{array}{l}\text { Assertive } \\
\text { message }\end{array}$ & $\begin{array}{l}\text { Sharing expectations, training assertiveness, } \\
\text { preventing conflict and increasing social support }\end{array}$ & $\begin{array}{l}\text { Reflexion, structured action planning and implementation } \\
\text { exercise. Participant reflects upon important people and } \\
\text { shares assertive message to them. Duration 5-15 min. }\end{array}$ \\
\hline & Appreciation & $\begin{array}{l}\text { Expressing appreciation, encouraging cooperation, } \\
\text { strengthening connection }\end{array}$ & $\begin{array}{l}\text { Reflexion, structured action planning and implementation } \\
\text { exercise. Participant shares ones needs and appreciation } \\
\text { with the partner. Duration 5-10 min. }\end{array}$ \\
\hline
\end{tabular}

they choose. This enables a participant to personalize the intervention to his needs. The participants are instructed that they will have access to BADI for one month.

\section{Participants \\ Inclusion criteria}

All individuals willing to participate in the study have to have adjustment difficulties and be no less than of 18 years old, have access to internet and a computer or a smart gadget with screen and audio output, and also have sufficient Lithuanian language literacy to understand the instructions and give informed consent.

\section{Exclusion criteria}

Risk of suicide, severe adjustment difficulties.

\section{Withdrawal criteria}

Individuals who wish to terminate their participation in the program are asked if they would consent to completing following assessments. If not, no further remainder e-mails or invitations to complete assessments are sent.

\section{Recruitment}

All participants are self-referred. Study is advertised via social media and media, and can be accessed via Facebook links, and media articles.

\section{Enrolment}

Participants interested in the study can register to the program at the intervention website. Eligible participants are then provided with detailed information about the study and are asked to give an informed consent. After giving informed consent and filling in the self-report measures of the initial assessment (T1) they are asked to wait until they are approved for the participation.

\section{Randomization}

The randomization process is continuous in a way that the participant is instantly allocated to the intervention 
or waiting-list control group within $24 \mathrm{~h}$ of completing the initial assessment. Randomization is conducted by study team member using an online true random number service www.random.org. Participants are randomized in 1:1 ratio to study groups. No stratification is applied.

\section{Blinding}

Participants are not blinded to possible groups. Participants are informed that after completing the baseline assessment they would be randomly assigned to one of the two groups: either to the one in which participant will instantly gain access to the BADI intervention or a group in which participants will be given access to the BADI program after waiting for one month.

\section{Study groups}

\section{Intervention BADI}

Participants in the intervention BADI group have full access to the intervention modules for 30 days. Participants can freely select any of the BADI intervention exercises. Participants can complete as many or as little exercises as they need. Participants can do exercises in any order they prefer. There are no instructions to complete all exercises. Participants can choose to complete one or more exercises and do them repeatedly. Weekly remainder e-mails are sent once per week to participants. Participants are reminded that for stress management skills to improve they need to use the intervention as frequently as possible.

\section{Waiting-list control}

Participants in the waiting-list control group are asked to continue with their everyday life and come back for a secondary assessment after 30 days, after completing the secondary assessment they receive access to the intervention for one month.

\section{Outcomes}

Self-report questionnaires are used for assessment of primary outcomes.

\section{Primary outcomes}

The main outcome measures are psychological wellbeing and severity of Adjustment disorder symptoms. Level of adjustment disorder symptom severity is evaluated with Adjustment disorder new model (ADNM-20) [28] questionnaire. This questionnaire is constructed of a stressors list and evaluation of symptoms. The list is composed of seven of acute events (e.g. divorce, moving) and nine chronic stressors (e.g. conflict with neighbours, serious illness). Participants are instructed to indicate all severe events from the list that they had experienced in the last 2 years and that caused significant level of stress.
There is also a blank item for participants to fill in other significant stressors. Psychometric properties of the Lithuanian version of the ADNM-20 questionnaire are acceptable [7].

The WHO-5 Well-being Index (WHO-5) [29] is a short self-report measure for well- being assessment. Participants are asked to rate how each of the 5 statements applies to them when considering the last 2 weeks. Each item is scored from 5 (all of the time) to 0 (none of the time). The raw score therefore ranges from 0 (absence of well-being) to 25 (highest well-being). Participants who score $>16$ on ADNM and $<50$ on WHO-5 are included into the study.

\section{Secondary outcomes}

Secondary outcomes are motivation to use the program, expectations for the intervention and engagement into the program. These outcomes are measured with tools incorporated into the program and self-report questionnaires at assessment time points.

Motivation is measured by a three item questionnaire created by the authors of this study. Expectations are measured as the difference of two 10-point Likert scale questions: 1) How do you feel today before starting the intervention BADI? 2) How do expect to feel after using the intervention BADI for one month? Participants are also asked to indicate how often they are planning to use the intervention in the upcoming month and the reasons for choosing this intervention. Engagement is measured by the number of exercises completed by the participant.

\section{Analysis}

\section{Sample size}

To achieve an improvement of 10 in mean scores of WHO-5 Well-being index we calculated about 73 participants per study arm to achieve $80 \%$ power at $\alpha=.05$. Factoring in the $30 \%$ attrition rate, we seek to randomize a total of 190 participants.

\section{Statistical analysis}

All data will be analysed using Statistical Package for the Social Sciences (SPSS) version 20. Differences between groups at baseline will be investigated using $X^{2}$ tests of independence for categorical measures and $t$-tests for continuous measures. Intent-to-treat approach will be applied to the primary efficacy analysis from $\mathrm{T} 1$ to $\mathrm{T} 2$. Per-protocol and completer analysis will be performed as secondary. Mixed ANOVA with post hoc tests will be used to test effect of time and interactions between groups in time. Cohens' $d$ will be calculated for estimation of within and between group effect sizes.

Drop-out is considered if a participant uses the program at least once but does not complete self-report at T2. Engagement in this study is defined by the number 
of exercises completed by participant, i.e., the more exercises a participant completes the more engaged participant is considered.

\section{Discussion}

Adjustment disorder might be a popular diagnosis [1], but there were only a few controlled clinical trials implemented to evaluate different treatment approaches for it [8]. First internet-based interventions for adjustment disorders were developed only recently and have not been evaluated in large scale empirical studies [8]. Therefore, we have developed BADI - a modular internet-based intervention for adjustment disorders. Users of this intervention do not have to complete all four modules (twelve exercises) in order to improve their condition. Rather they can test and choose modules and exercises which they like most and find useful. This is different from the linear approach, where users have to complete certain steps before they can progress to others.

We believe that a modular approach to internet-based intervention for adjustment disorders has several important benefits. Adjustment disorders can be caused by very different stressors therefore interventions should also reflect this variety, if they are targeting at the general population. Availability of different modules also means that users can choose according to their needs and preferences. And finally a modular approach provides flexibility for users - they can use the intervention whenever they need it and spend as much time as they feel appropriate. Thus it gives participants a sense of control, something that is important when facing stressful life events that may seem out of control.

BADI consists of 4 modules: Relaxation, Time management, Mindfulness and Strengthening relationships. It is based on stress and coping research and integrates evidence based modern treatment approaches such as Cognitive Behavioural therapy (CBT), mindfulness and body-mind practices, as well as exercises for enhancing social support. In this respect it differs from eHealth intervention developed by Maercker team [8], where PTSD treatment techniques such as written narrative exposition are also included.

In addition to evaluating effectiveness of BADI intervention, it will also examine correlations between effectiveness, motivation, expectations, drop-out and adherence. We believe that is important to look for new ways how to understand and measure drop-outs and adherence in the context of fully automated internet-based interventions as they are very different from traditional face-to-face interventions.

In case this RCT supports effectiveness of a fully automated version of BADI, it could be used very broadly. BADI could become a very cost-effective and accessible intervention for adjustment disorder.

\section{Abbreviations}

BADI, brief adjustment disorder intervention; CBT, cognitive behavioural therapy; DSM, diagnostic and statistical manual of mental disorders; ICD, international classification of diseases; PTSD, post-traumatic stress disorder; $\mathrm{RCT}$, randomized controlled trial.

\section{Acknowledgments}

Not applicable.

\section{Funding}

This research was funded by a grant (MIP-079/2014) from the Research Council of Lithuania.

Availability of data and material

Not applicable, as this is a study protocol.

Authors' contributions

PS was involved in development of BADI intervention, drafted Background and Discussion sections of the manuscript. JE has planned the study, significantly contributed to BADI intervention development, and drafted Methods/Design section of the manuscript, and made significant contributions to other sections of the manuscript. MD was involved in development of BADI intervention and described BADI modules in the manuscript. EM was involved in development of BADI intervention, reviewed the draft of the manuscript and made significant contributions to it. PZ was involved in development of BADI intervention, reviewed the draft of the manuscript and made significant contributions to it. EK has planned the study, was involved in development of BADI intervention, reviewed the draft of the manuscript and made significant contributions to it.

\section{Competing interests}

The authors declare that they have no competing interests.

Consent for publication

Not applicable.

\section{Ethics approval and consent to participate}

The study was approved by Vilnius University Psychology Research Ethics Committee. Participants are provided with detailed information about the study and are asked to give an informed consent prior to the intervention.

\section{Author details}

${ }^{1}$ Department of Clinical and Organizational Psychology, Vilnius University, Universiteto str. 9/1, Vilnius 01513, Lithuania. ${ }^{2}$ Department of General

Psychology, Vilnius University, Universiteto str. 9/1, Vilnius 01513, Lithuania.

Received: 6 July 2016 Accepted: 15 July 2016

Published online: 26 July 2016

\section{References}

1. Evans SC, Reed GM, Roberts MC, et al. Psychologists' perspectives on the diagnostic classification of mental disorders: results from the WHO-IUPsyS Global Survey. Int J Psychol. 2013;48(3):177-93. doi:10.1080/00207594.2013.804189.

2. Maercker A, Forstmeier S, Pielmaier L, Spangenberg L, Brahler E, Glaesmer H. Adjustment disorders: prevalence in a representative nationwide survey in Germany. Soc Psychiatry Psychiatr Epidemiol. 2012;47(11):1745-52. doi:10.1007/ s00127-012-0493-x.

3. Maercker A, Brewin CR, Bryant $R$, et al. Proposals for mental disorders specifi cally associated with stress in the International Classifi cation of Diseases-11. Lancet. 2013;381(9878):1683-5. doi:10.1016/S0140-6736(12)62191-6.

4. Maercker A, Brewin CR, Bryant R, et al. Diagnosis and classification of disorders specifically associated with stress: Proposals for ICD-11. World Psychiatry. 2013;12(3):198-206. doi:10.1002/wps.20057.

5. Casey P. Adjustment disorder: new developments. Curr Psychiatry Rep. 2014;16(6):1-8. doi:10.1007/s11920-014-0451-2.

6. Maercker A, Einsle F, Köllner V. Adjustment disorders as stress response syndromes: a new diagnostic concept and its exploration in a medical sample. Psychopathology. 2007;40(3):135-46. doi:10.1159/000099290.

7. Zelviene P, Kazlauskas E, Eimontas J, Maercker A. Adjustment disorder: Empirical study of a new diagnostic concept for ICD-11 in the general 
population in Lithuania. Eur Psychiatry. doi:10.1016/j.eurpsy.2016.06.009 (in press).

8. Maercker A, Bachem RC, Lorenz L, Moser CT, Berger T. Adjustment disorders are uniquely suited for ehealth interventions: concept and case study. JMIR Ment Heal. 2015;2(2):e15. doi:10.2196/mental.4157.

9. Strain JJ, Diefenbacher A. The adjustment disorders: the conundrums of the diagnoses. Compr Psychiatry. 2008:49(2):121-30. doi:10.1016/j.comppsych.2007. 10.002 .

10. Sloan DM, Gallagher MW, Feinstein BA, Lee DJ, Pruneau GM. Efficacy of telehealth treatments for posttraumatic stress-related symptoms: a metaanalysis. Cogn Behav Ther. 2011;6073(May 2016):1-15. doi:10.1080/16506073.2010.550058.

11. Hoge CW, Castro CA, Messer SC, McGurk D, Cotting DI, Koffman RL. Combat duty in Iraq and Afghanistan, mental health problems, and barriers to care. N Engl J Med. 2004;351(1):13-22. doi:10.1056/NEJMoa040603.

12. Barak A, Hen L, Boniel-Nissim M, Shapira N. A comprehensive review and a meta-analysis of the effectiveness of internet-based psychotherapeutic interventions. J Technol Hum Serv. 2008;26(2-4):109-60. doi:10.1080/15228830802094429.

13. Eysenbach G. CONSORT-EHEALTH: improving and standardizing evaluation reports of Web-based and mobile health interventions. J Med Internet Res, 2011;13(4):e126. doi:10.2196/jmir.1923.

14. Ghafari S, Ahmadi F, Nabavi M, et al. Effectiveness of applying progressive muscle relaxation technique on quality of life of patients with multiple sclerosis. J Clin Nurs. 2009;18(15):2171-9. doi:10.1111/j.1365-2702.2009.02787.x.

15. Rausch SM, Gramling SE, Auerbach SM. Effects of a Single Session of LargeGroup Meditation and Progressive Muscle Relaxation Training on Stress Reduction, Reactivity, and Recovery. Int J Stress Manag. 2006;13(3):273-90,

16. Feldman G, Greeson J, Senville J. Differential effects of mindful breathing, progressive muscle relaxation, and loving-kindness meditation on decentering and negative reactions to repetitive thoughts. Behav Res Ther. 2010;48(10):1002-11.

17. Brown KW, Ryan RM. The benefits of being present: mindfulness and its role in psychological well-being. J Pers Soc Psychol. 2003;84(4):822-48.

18. Davis M, Eshelman ER, McKay M. The Relaxation and Stress Reduction Workbook. 6th ed. Oakland: New Harbinger Publications; 2008.

19. Ogden P. Emotion, mindfulness and movement: Expanding the regulatory boundaries of the window of tolerance. In: Fosha D, Siegel DJ, Solomon M, editors. The Healing Power of Emotion: Perspectives from Affective Neuroscience and Clinical Practice. New York: W.W. Norton; 2009.

20. Ogden P, Minton K, Pain C. Trauma and the body: a sensorimotor approach to psychotherapy. New York: W.W. Norton; 2006.

21. Lazarus RS, Folkman S. Stress, appraisal and coping. New York: Springer Publishing Company; 1984

22. Penley JA, Tomaka J, Wiebe JS. The association of coping to physical and psychological health outcomes: a meta-analytic review. J Behav Med. 2002; 25(6):551-603. doi:10.1023/A:1020641400589

23. Carmody J, Baer RA. Relationships between mindfulness practice and levels of mindfulness, medical and psychological symptoms and well-being in a mindfulness-based stress reduction program. J Behav Med. 2008:31(1):23-33.

24. Kabat-Zinn J. Mindfulness-based interventions in context: Past, present, and future. Clin Psychol Sci Pract. 2003;10(2):144-56.

25. Ramel W, Goldin PR, Carmona PE, McQuaid JR. The effects of mindfulness meditation on cognitive processes and affect in patients with past depression. Cogn Ther Res. 2004;28(4):433-55. doi:10.1023/B:COTR. 0000045557.15923 .96$.

26. Vasionyte I, Dovydaitienè M. Démesingu jsisąmoninimu pagristos streso mažinimo programos dalyviu subjektyvus efektyvumo vertinimas [Subjective effectiveness of mindfulness-based stress reduction program]. Biol Psichiatr ir Psichofarmakol. 2015;17(28-33):3-8.

27. Leach J. Improving mental health through social support: building positive and empowering relationships. London: Jessica Kingsley Publishers; 2015.

28. Maercker A, Forstmeier S, Enzler A, et al. Adjustment disorders, posttraumatic stress disorder, and depressive disorders in old age: findings from a community survey. Compr Psychiatry. 2008;49(2):113-20. doi:10.1016/j.comppsych.2007.07.002.

29. World Health Organization. Info package: mastering depression in primary care, version 2.2. WHO, Regional Office for Europe. Psychiatric Research Unit, Frederiksborg; 1998.

\section{Submit your next manuscript to BioMed Central and we will help you at every step:}

- We accept pre-submission inquiries

- Our selector tool helps you to find the most relevant journal

- We provide round the clock customer support

- Convenient online submission

- Thorough peer review

- Inclusion in PubMed and all major indexing services

- Maximum visibility for your research

Submit your manuscript at www.biomedcentral.com/submit

) Biomed Central 